\title{
Penghitungan vektor-kharakteristik secara iteratif menggunakan titik tetap Brouwer
}

\author{
Subiono \\ Jurusan Matematika, FMIPA-ITS, Surabaya \\ Email: subiono2008@matematika.its.ac.id
}

\begin{abstract}
Abstrak
Dalam paper ini diturunkan suatu cara iteratif untuk menghitung vektor karakateristik suatu matriks bujur sangkar $A$ yang bersesuaian dengan nilai kharakteristik $\lambda$ dimana nilai kharakteristik ini sama dengan radius spektral dari matriks $A$. Matriks $A$ yang dibahas mempunyai elemenelemen positip, selanjutnya melaui matriks $A$ dibentuk pemetaan linear. Pemetaan linear ini dimodifikasi dengan suatu pembobot norm vektor. Pemetaan termodifikasi ini kontinu dan ditunjukkan bahwa pemetaan ini mempunyai titik tetap Brouwer yang merupakan vektor karakteristik dari matriks $A$.
\end{abstract}

Kata kunci: Titik tetap Brouwer, matriks positip, norm vektor, radius spektral matriks.

\section{Pendahuluan}

Dalam paper ini dibahas suatu cara iteratif untuk menghitung suatu vektorkharakteristik dari suatu matriks bujur sangkar. Cara iteratif ini adalah suatu hasil rekayasa dengan memodifikasi matriks bujur sangkar yang akan dihitung vektor-kharakteristiknya dengan suatu pembobot norm vektor.

Kajian berkaitan dengan cara iteratif untuk menghitung vektor kharakteristik yang bersesuaian dengan nilai kharakteristik dari suatu matriks bujur sangkar dengan menggunakan titik tetap Banach dibahas dalam [1]. Disini diberikan beberapa contoh matriks bujur sangkar, lalu dimodifikasi setelah itu dibentuk pemetaan linear dan dicari titik tetapnya. Pemetaan linear yang terbentuk ada yang mempunyai titik tetap ada yang tidak mempunyai. Dalam paper ini dikaji secara khusus untuk matriks bujur sangkar dengan elemenelemen yang positif dinamakan matriks positif. Matriks bujur sangkar positif adalah matriks yang taktereduksi dan dijamin mempunyai nilai kharakteristik positif yang merupakan radius spektralnya [2]. Selanjutnya matriks taktereduksi ini dimodifikasi dengan suatu pembobot norm vektor. Pemodifikasian ini dilakukan supaya diperoleh suatu pemetaan kontinu pada bola $B \subset \mathbb{R}^{n}$ dimana $B=\left\{x:\|x\|_{\infty} \leq 1, x \neq \mathbf{0}\right\}$. Pemetaan ini mempunyai titik tetap yang dinamakan titik tetap Brouwer ([4]). Dalam hal ini suatu hasil yang lebih baik diperoleh, yaitu cara iteratif di [1] hanya memperoleh vektor-kharakteristik, dan nilai-kharakteristiknya sudah dihitung sebelumnya, sedangkan cara iteratif 
dalam pembahasan ini akan diperoleh secara langsung nilai-kharakteristik dan juga vektor-kharakteristik yang sesuai dengan nilai-kharakteristiknya.

Matriks taktereduksi erat kaitannya dengan matriks taknegatif (elemenelemennya boleh nol). Suatu pembahasan yang rinci dari matriks taknegatif bisa dijumpai di [3]. Sedangkan pembahasan berkaitan dengan masalah titik tetap Brouwer bisa dilihat di [4].

\section{Norm vektor dan teorema titik tetap Brouwer.}

Pada bagian ini akan diberikan pengertian yang berkenaan dengan norm vektor. Pengertian ini akan digunakan dalam pembahasan berikutnya yang berkaitan dengan masalah titik tetap Brouwer.

\section{Norm vektor}

Norm dari suatu vektor $x \in \mathbb{R}^{n}$ dinotasikan oleh $\|x\|$ adalah suatu fungsi bernilai real yang memenuhi kondisi berikut : untuk setiap $x$ dan $y$ di $\mathbb{R}^{n}$

$1\|x\| \geq 0$.

$2\|x\|=0$ bila dan hanya bila $x=\mathbf{0}$.

$3\|c x\|=|c|\|x\|$ untuk setiap skalar $c$.

$4\|x+y\| \leq\|x\|+\|y\|$.

Ada beberapa macam norm vektor, tetapi disini yang diperlukan adalah norm takhingga yang dinotasikan oleh $\|\cdot\|_{\infty}$ dan didifinisikan sebagai:

$$
\|x\|_{\infty}=\max \left\{\left|x_{1}\right|,\left|x_{2}\right|, \ldots,\left|x_{n}\right|\right\},
$$

dimana $x=\left[x_{1}, x_{2}, \ldots, x_{n}\right]^{\prime}$.

Contoh 1. Diberikan matriks

$$
A=\left(\begin{array}{ll}
1 & 2 \\
3 & 4
\end{array}\right) \text { dan vektor } x=\left(\begin{array}{l}
1 \\
0
\end{array}\right) \text {, maka }\|A x\|_{\infty}=3 .
$$

\section{Teorema Titik Tetap Brouwer.}

Misalkan $B=\left\{x:\|x\|_{\infty} \leq 1, x \neq \mathbf{0}\right\}$ adalah bola di $\mathbb{R}^{n}$ dan pemetaan $f: B \longrightarrow B$ kontinu, maka $f$ mempunyai suatu titik tetap di $B$.

Teorema Titik tetap Brouwer ini adalah suatu konsekuensi sederhana dari teorema nilai-tengah untuk fungsi kontinu pada interval tutup $[a, b]$ dengan $f(x)=$ $x$. Ada suatu hasil analogi di $\mathbb{R}^{n}$ dalam hal ini dikenal sebagai Teorema Titik tetap Brouwer yang sangat begitu jauh dari kejelasan. Bukti lengkap dari Teorema Titik tetap Brouwer bisa diikuti di [4]. 


\section{Matriks positif.}

Suatu matriks bujur sangkar $A$ adalah matriks positif bila semua elemen-elemennya lebih besar dari pada nol ditulis $A>\mathbf{0}$. Sedangkan matriks bujur sangkar $A$ adalah matriks taknegatif bila semua elemen-elemennya lebih besar atau sama dengan nol ditulis $A \geq \mathbf{0}$. Harga mutlak terbesar dari semua nilai kharakteristik suatu matriks bujur sangkar $A$ dinamakan radius spektral dari $A$, ditulis $\sigma(A)$.

Matriks bujur sangkar $A \geq \mathbf{0}$ dikatakan matriks yang dapat-direduksi, bila ada matriks permutasi $P$ sehingga:

$$
P A P^{\prime}=\left(\begin{array}{ccc}
A_{11} & \vdots & A_{21} \\
\cdots & \cdot & \cdots \\
0 & \vdots & A_{22}
\end{array}\right),
$$

dengan masing-masing matriks $A_{11}$ dan $A_{22}$ adalah matriks bujur sangkar berukuran lebih kecil dari pada ukuran matriks $A$. Bila tidak ada matriks permutasi $P$ yang memenuhi (1), maka dikatakan matriks $A$ taktereduksi. Beberapa hasil menarik dari matrik positif dan matriks taknegatif diberikan dalam beberapa sifat berikut ini.

- Sifat 1. Matriks positif adalah tak-teredusi.

- Sifat 2. Suatu matriks $A \geq \mathbf{0}$ berukuran $n \times n$ tak-tereduksi, bila dan hanya bila $(I+A)^{n-1}>\mathbf{0}$.

- Sifat 3. (Teorema Perron-Frobenius) Suatu matriks $A \geq 0$ taktereduksi mempunyai nilai-kharakteristik dengan multiplisitas satu sama dengan $\sigma(A)$ dan vektor-kharakteristik yang bersesuaian dengan nilai kharakteristik $\sigma(A)$ elemen-elemennya positif.

Kajian yang lengkap berkenaan dengan matriks tak-negatif dan positif bisa diikuti di [2] atau di [3]. Berikut ini diberikan satu contoh, contoh ini akan dikaji lagi dalam bagian berikutnya.

Contoh 2. Diberikan matriks tak-negatif

$A=\left(\begin{array}{ll}0 & 1 \\ 6 & 1\end{array}\right)$ maka salah satu nilai-kharakteristiknya adalah 3 , sedangkan vektor-kharakteristik yang bersesuaian adalah $x=\left(\begin{array}{c}0.3333333 \\ 1\end{array}\right)$. Matriks A tak-tereduksi, sebab $(I+A)>\mathbf{0}$. Dalam hal ini $\sigma(A)=3$, nilai-kharakteristik yang lain adalah - 2 .

\section{Penghitungan vektor-kharakteristik secara ite- ratif}

Pada bagian ini diberikan cara menghitung vektor-kharakteristik secara iteratif dari suatu matriks bujur sangkar $A>\mathbf{0}$. Matriks $A$ membentuk suatu 
pemetaan dan dilakukan pembobotan pada pemetaan ini dengan suatu norm vektor, hasilnya adalah suatu pemetaan yang kontinu di $B \subset \mathbb{R}^{n}$ dimana $B=$ $\left\{x:\|x\|_{\infty} \leq 1, x \neq \mathbf{0}\right\}$.

Pembobotan dengan norm vektor yang telah disebutkan dilakukan sebagaimana berikut ini. Diberikan suatu matrik $A>\mathbf{0}$ berukuran $n \times n$ dan vektor $x \in B \subset \mathbb{R}^{n}$ dimana $B=\left\{x:\|x\|_{\infty} \leq 1, x \neq \mathbf{0}\right\}$. Pemetaan $p: B \longrightarrow B$ dengan $p(x)=A x, \forall x \in B$ adalah pemetaan linear. Selanjutnya dibentuk suatu pembobot $\frac{1}{\|p(x)\|_{\infty}}=\frac{1}{\|A x\|_{\infty}}$. Untuk memperoleh titik tetap Brouwer dibuat suatu pemetaan $f: B \longrightarrow B$ dimana $f(x)=\frac{1}{\|A x\|_{\infty}} A x$. Pemetaan $f($.$) adalah$ kontinu sebab pemetaan $p($.$) dan \frac{1}{\|\cdot\|_{\infty}}$ kontinu, dengan menggunakan Teorema Titik Tetap Brouwer, pemetaan $f($.$) dijamin mempunyai suatu titik tetap.$

Teorema berikut ini merupakan hasil dari pembahasan yang berkaitan dengan pembentukan pemetaan $f($.$) dan teorema ini nantinya berguna untuk$ menghitung secara iteratif nilai-kharakteristik dan juga vektor-kharakteristik yang bersesuaian dengan nilai-kharakteristik matriks $A$.

\section{Teorema}

Bila matriks $A>\mathbf{0}$ dan pemetaan $f: B \rightarrow B$ dengan $f(x)=\frac{1}{\|A x\|_{\infty}} A x$ dan $B=\left\{x:\|x\|_{\infty} \leq 1, x \neq \mathbf{0}\right\}$, maka nilai-kharakteristik dan vektor-kharakteristik yang bersesuaian dengan nilai-kharakteristik dari matriks A masing-masing diberikan oleh $\|A y\|_{\infty}$ dan y untuk suatu $y \in B$.

\section{Bukti}

Menurut Teorema Titik Tetap Brouwer, pemetaan $f($.$) mempunyai suatu titik$ tetap (sebab $f($.$) kontinu sebagaimana diberikan dalam pembahasan sebelum-$ nya). Misalkan titik tetap ini adalah $y$. Jadi $y=\frac{1}{\|A y\|_{\infty}} A y$ atau $A y=$ $\|A y\|_{\infty} y$. Terlihat bahwa $\|A y\|_{\infty}$ adalah nilai-kharakteristik dari $A$ dan vektorkharakteristik yang bersesuaian diberikan oleh $y$.

Untuk melakukan penghitungan vektor-kharakteristik dan nilai-kharakteristik dari suatu matriks $A>\mathbf{0}$ secara iteratif dengan menggunakan hasil Teorema terakhir diatas, lakukan langkah-langkah berikut:

1. Pilih sebarang vektor $x=x_{0} \in B$ (sebagai nilai awal).

(2). Hitung $x_{1}=\frac{1}{\left\|A x_{0}\right\|_{\infty}} A x_{0}$.

(3). Lakukan lagi langkah (2) terus-menerus, tetapi untuk nilai awal $x_{1}$.

(4). Berhenti bila dalam langkah (3) sudah memberikan suatu nilai yang tetap. 
Tabel 1: Hasil iterasi Contoh 3.

\begin{tabular}{|c|c|c||c|c|c|}
\hline \hline No. & $\begin{array}{c}\text { Vektor } \\
\text { Kharakteristik }\end{array}$ & $\begin{array}{c}\text { Nilai } \\
\text { Kharakteristik }\end{array}$ & No. & $\begin{array}{c}\text { Vektor } \\
\text { Kharakteristik }\end{array}$ & $\begin{array}{c}\text { Nilai } \\
\text { Kharakteristik }\end{array}$ \\
\hline \hline 1 & {$[1,1]$} & 7 & 24 & {$[0.3333003,1]$} & 2.999802 \\
2 & {$[0.1428571,1]$} & 1.8571429 & 25 & {$[0.3333553,1]$} & 3.000132 \\
3 & {$[0.5384615,1]$} & 4.2307692 & 26 & {$[0.3333187,1]$} & 2.999912 \\
4 & {$[0.2363636,1]$} & 2.4181818 & 27 & {$[0.3333431,1]$} & 3.0000587 \\
5 & {$[0.4135338,1]$} & 3.481203 & 28 & {$[0.3333268,1]$} & 2.9999609 \\
6 & {$[0.2872570,1]$} & 2.7235421 & 29 & {$[0.3333377,1]$} & 3.0000261 \\
7 & {$[0.3671689,1]$} & 3.2030135 & 30 & {$[0.3333304,1]$} & 2.9999826 \\
8 & {$[0.3122060,1]$} & 2.8732359 & 31 & {$[0.3333353,1]$} & 3.0000116 \\
9 & {$[0.3480396,1]$} & 3.0882378 & 32 & {$[0.3333320,1]$} & 2.9999923 \\
10 & {$[0.3238093,1]$} & 2.9428555 & 33 & {$[0.3333342,1]$} & 3.0000052 \\
11 & {$[0.3398060,1]$} & 3.0388361 & 34 & {$[0.3333328,1]$} & 2.9999966 \\
12 & {$[0.3290734,1]$} & 2.9744402 & 35 & {$[0.3333337,1]$} & 3.0000023 \\
13 & {$[0.3361977,1]$} & 3.0171863 & 36 & {$[0.3333331,1]$} & 2.9999985 \\
14 & {$[0.3314346,1]$} & 2.9886077 & 37 & {$[0.3333335,1]$} & 3.000001 \\
15 & {$[0.3346040,1]$} & 3.0076238 & 38 & {$[0.3333332,1]$} & 2.9999993 \\
16 & {$[0.3324884,1]$} & 2.9949303 & 39 & {$[0.3333334,1]$} & 3.0000005 \\
17 & {$[0.3338976,1]$} & 3.0033855 & 40 & {$[0.3333333,1]$} & 2.9999997 \\
18 & {$[0.3329576,1]$} & 2.9977456 & 41 & {$[0.3333334,1]$} & 3.0000002 \\
19 & {$[0.3335840,1]$} & 3.0015041 & 42 & {$[0.3333333,1]$} & 2.9999999 \\
20 & {$[0.3331663,1]$} & 2.9989978 & 43 & {$[0.3333333,1]$} & 3.0000001 \\
21 & {$[0.3334447,1]$} & 3.0006684 & 44 & {$[0.3333333,1]$} & 2.9999999 \\
22 & {$[0.3332591,1]$} & 2.9995545 & 45 & {$[0.3333333,1]$} & 3. \\
23 & {$[0.3333828,1]$} & 3.000297 & 46 & {$[0.3333333,1]$} & 3. \\
\hline \hline
\end{tabular}

Contoh 3. Contoh 2 dibahas lagi sebagai berikut. Matriks

$$
A=\left(\begin{array}{ll}
0 & 1 \\
6 & 1
\end{array}\right)
$$

Untuk nilai awal $x_{0}=[0,1]^{\prime}$, hasil penghitungan iterasi diberikan oleh Tabel 1 . Dalam Tabel 1, terlihat bahwa titik tetap terjadi pada iterasi ke-45 dan hasilnya sama seperti dalam Contoh 2.

Perluh diperhatikan bahwa hitungan secara iterasi ini dilakukan dengan bantuan perangkat lunak Scilab v 3.1.1. yang bisa di download secara gratis. Perangkat lunak ini hampir mirip dengan perangkat lunak yang banyak dikenal dalam penghitungan matriks, yaitu Matlab. Sebagai akhir bagian ini, diberikan lagi satu contoh, tetapi untuk suatu matriks dengan ukuran $10 \times 10$. 
Contoh 4. Diberikan matriks

$$
A=\left(\begin{array}{cccccccccc}
8 & 7 & 4 & 3 & 5 & 3 & 3 & 6 & 8 & 10 \\
5 & 4 & 9 & 3 & 4 & 3 & 5 & 8 & 1 & 8 \\
2 & 3 & 9 & 3 & 7 & 9 & 1 & 5 & 6 & 4 \\
7 & 2 & 6 & 5 & 6 & 7 & 10 & 6 & 1 & 5 \\
8 & 2 & 5 & 7 & 8 & 1 & 6 & 2 & 4 & 2 \\
1 & 7 & 9 & 3 & 10 & 1 & 4 & 4 & 3 & 6 \\
7 & 3 & 8 & 8 & 5 & 9 & 5 & 8 & 9 & 3 \\
4 & 5 & 6 & 6 & 9 & 2 & 3 & 7 & 0 & 10 \\
8 & 2 & 8 & 4 & 2 & 3 & 4 & 5 & 8 & 7 \\
5 & 7 & 7 & 7 & 10 & 7 & 2 & 6 & 10 & 4
\end{array}\right) \text { iterasi awal } x_{0}=\left(\begin{array}{c}
1 \\
0 \\
0 \\
0 \\
0 \\
0 \\
0 \\
0 \\
0 \\
0
\end{array}\right)
$$

Dengan menggunakan bantuan Scilab v 3.1.1., hasil iterasi ke-8 sudah memberikan vektor-kharakteristik

$$
x=\left(\begin{array}{l}
0.9041 \\
0.7893 \\
0.7247 \\
0.8733 \\
0.7083 \\
0.7177 \\
1.0000 \\
0.8321 \\
0.8090 \\
0.9809
\end{array}\right) \text { dan nilai }- \text { kharakteristiknya adalah } \lambda=141.7294 .
$$

\section{Penutup}

Sebagai akhir dari bahasan diberikan beberapa catatan yang diharapkan dapat bermanfaat untuk kajian mendatang. Ada suatu hal yang menarik dalam Contoh 3 dan Contoh 4 . Iterasi dalam Contoh 3 untuk mencapai titik tetap terjadi pada iterasi yang agak panjang yaitu iterasi ke-45 padahal ukuran matriknya relatif kecil yaitu $2 \times 2$, sedangkan dalam Contoh 4 , ukuran matriknya cukup besar dibandingkan dalam Contoh 3 , tetapi disini pencapaian titik tetap cukup singkat dibandingkan dalam Contoh 3, yaitu terjadi pada iterasi ke-8. Untuk menyimpulkan mengapa hal ini bisa terjadi secara teoritis sangat memungkinkan sulit terjawab. Hal lain yang menarik adalah penyelidikan bila memungkinkan cara iteratif ini dimodifikasi sehingga pencapaian titik tetap lebih cepat tercapai. Bila hal ini bisa terjadi, tentunya sangat bermanfaat untuk penghitungan vektor-kharakteristik dan nilai-kharakteristik yang sesuai dari suatu matriks yang ukurannya sangat cukup besar dan tentunya hal ini sangat berguna dalam dunia praktis.

\section{Daftar Pustaka}

[1] Ratna Novitasari,(2005), Kajian Teorema Titik Tetap Banach Serta Aplikasinya Pada Model Linear dan Pada Masalah Nilai Eigen dan Vektor Eigen, Tugas Akhir S1, Matematika-ITS. 
[2] Rumita Sari, (2005), Kajian Teorema Perron Frobenius dan Applikasi Matriks Nonnegatif Irreducible Pada Model Genetika, Tugas Akhir S1, Matematika-ITS.

[3] A. Graham, (1987), Nonnegative Matrices and Applicable Topics in Linear Algebra, Wiley \& Sons, New York.

[4] J.R.L. Webb, (1991), Functions of several real variables, Ellis Horwood Limited, England. 